\title{
Indian Research Society for the Study of Diabetes in India (RSSDI) recommendations for diabetes management: A psychosocial commentary
}

\author{
Sanjay Kalra, Sarita Bajaj ${ }^{1}$, Ashok Kumar Das ${ }^{2}$ \\ Department of Endocrinology, Bharti Hospital, Karnal, Haryana, India, ${ }^{1}$ Department of Medicine, Moti Lal Nehru (MLN) Medical College, \\ Allahabad, Uttar Pradesh, India, ${ }^{2}$ Department of Endocrinology, Pondicherry Institute of Medical Sciences, Pondicherry, India
}

The Research Society for the Study of Diabetes in India (RSSDI) recently released comprehensive clinical practice recommendations for the management of type 2 diabetes mellitus (T2DM) ${ }^{[1]}$ The published document is a "derived guideline," developed from the International Diabetes Federation (IDF) Global Guideline for type 2 Diabetes. ${ }^{[2]}$ The authors of the RSSDI recommendations have fulfilled a major felt need for the Indian diabetes care community by providing practical and pragmatic guidance that is relevant for and suited to the Indian content.

In this editorial, we focus on the aspects of diabetes care specific to India, covered in the RSSDI document, and discuss how maximal utility can be gained from the coverage of these topics.

The Indian recommendations are structured into 20 sections, including the preface and annexure, while most of the contents are similar to the recommended care and limited care versions of the IDF guidelines, some sections merit special attention because of their novel suggestions. These include prediabetes, diet therapy, lifestyle management, targets of glucose control, footcare, fasting, and diabetes.

\section{PREDIABETES}

RSSDI has included detailed coverage of prediabetes in its diabetes management recommendations. This has

\begin{tabular}{|l|l|}
\hline \multicolumn{2}{|c|}{ Access this article online } \\
\hline Quick Response Code: & Website: \\
\hline & www.joshd.net \\
\cline { 2 - 2 } & \\
\hline & \\
\hline
\end{tabular}

been done keeping in mind the high prevalence of this condition in India. ${ }^{[3]}$

The diagnostic cutoffs and treatment strategies are similar to internationally accepted practices. Screening should be linked to health care systems or national programs that have the capacity to provide lifestyle advice. Pharmacotherapy, including metformin, acarbose, or voglibose is recommended in persons with prediabetes who do not respond to lifestyle modification after 6 months. ${ }^{[4]}$ This aggressive, but much-needed stance by the Indian recommendation writers must be appreciated.

\section{LIfESTYLE MANAgeMENT: YOgA}

Yoga is included as a separate section in the discussion on lifestyle management. Yoga is described as a mind - body therapy, an old, traditional, Indian psychological; physical; and spiritual exercise regimen, and as a holistic philosophy. This includes not only physical exercises, but lifestyle and behavioral changes as well. The impact of yoga on the endocrine system, the autonomous nervous system, glucose control, and anthropometric measurements is well-documented. ${ }^{[5]}$

The recommendations appreciate the beneficial effect of yogic practices on the control of glycemia, blood pressure,

This is an open access article distributed under the terms of the Creative Commons Attribution-NonCommercial-ShareAlike 3.0 License, which allows others to remix, tweak, and build upon the work non-commercially, as long as the author is credited and the new creations are licensed under the identical terms.

How to cite this article: Kalra S, Bajaj S, Das AK. Indian Research Society for the Study of Diabetes in India (RSSDI) recommendations for diabetes management: A psychosocial commentary. J Soc Health Diabetes 2016;4:1-2.

Corresponding Author: Dr. Sanjay Kalra, Department of Endocrinology, Bharti Hospital, Karnal, Haryana, India.

E-mail: brideknl@gmail.com 
dyslipidemia, insulin resistance/hyperinsulinemia, and stress. Yoga practices are suggested for $30 \mathrm{~min} /$ day, in combination with other forms of physical activity, and for 45-60 min/day, if performed without other physical exercise.

\section{Alternative THERAPIES}

The RSSDI recommendations are categorical in stating that "clinicians trained in modern system of medicine are advised not to prescribe alternate therapies to treat diabetes." The discussion acknowledges the use of Ayurveda, Yoga, Unani, Siddha, and Homeopathy (AYUSH) and Naturopathy in diabetes care, and the various plant and mineral products used in diabetes management. It allows the use of "yoga, pranayama, meditations, and relaxation techniques" in vogue in India as supplements to nonpharmacological therapies.

It is important to note the clear-cut recommendation by the RSSDI, and limit prescription to modern drugs that are backed by evidence.

\section{DIET THERAPY}

The traditional Indian diet is quite different from those of other nations. The RSSDI document highlights this by specifying guidance that is important for Indians. The cardioprotective diet that is prescribed by the RSSDI is based upon Indian preferences. Dal and roti and rice and curry are suggested as Indian examples of mixed meals, with low glycemic index. Brown rice is preferred to polished white rice.

\section{TARgets Of Glucose Control}

The Indian recommendations follow global practice in promoting a glycated hemoglobin (HbA1C) target of $7.0 \%$ in diabetes management. ${ }^{[2]}$ For fasting and postprandial glucose, however, specific targets of $115 \mathrm{mg} \%$ and $160 \mathrm{mg} \%$ have been mentioned. It is further clarified that measurement of plasma glucose levels alone (without $\mathrm{HbA1c}$ assessment) may have to suffice in very limited resource settings. However, the rationale for choosing these cutoffs is not clear.

\section{FOOTCARE}

RSSDI appreciates the common practice of walking barefoot as a significant contributor of diabetic foot complications in India. ${ }^{[6]}$ The recommendation panel emphasizes the need to educate patients regarding the avoidance of walking barefoot and the use of appropriate therapeutic footwear. Economical off-loading devices such as the Mandakini offloading device and Samadhan system have been mentioned.

\section{FASTING AND DIABETES}

The section on management of diabetes during fasting does not distinguish between recommended care and limited care. It describes the various types of fasts (complete, partial) and lists factors related to fasting, glucose-lowering therapy, and individual patient characteristics that influence diabetes management during fasting. ${ }^{[7]}$ The recommendation enumerates clinical situations in which fasting should be avoided or discouraged, and suggests simple measures to ensure patient safety. The coverage of fasts from all major Indian religions, including Hinduism, Islam, and Jainism is a welcome feature of the document.

\section{SUMMARY}

This editorial touches upon some of the psychosocial and country-specific biomedical aspects of diabetes care covered in the RSSDI clinical practice recommendations for the management of T2DM. Such coverage adds value to existing global recommendations, and offers useful guidance to diabetes care providers working in unique sociocultural environments. It additionally serves as an example for other countries and regions to incorporate topic-specificity to their diabetes ecology. Ongoing focus on good quality indigenous research, designed to find objective evidence related to these unique facets of diabetology, will help enhance the importance and reliability of future editions of this recommendation.

\section{REFERENCES}

1. Madhu SV, Saboo B, Makkar BM, Reddy GC, Jana J, Panda JK, et al.; Guideline Development Group. RSSDI clinical practice recommendations for management of type 2 diabetes mellitus, 2015. Int J Diabetes Dev Ctries 2015;35:1-71.

2. Global Guideline for Type 2 Diabetes. Available from: http://www. idf.org/guideline-type-2-diabetes. [Last accessed on 2015 Dec 4].

3. Gujral UP, Narayan KM, Pradeepa RG, Deepa M, Ali MK, Anjana RM, et al. Comparing type 2 diabetes, prediabetes, and their associated risk factors in Asian Indians in India and in the U.S.: The CARRS and MASALA Studies. Diabetes Care 2015; 38:1312-8.

4. Choudhary N, Kalra S, Unnikrishnan AG, Ajish TP. Preventive pharmacotherapy in type 2 diabetes mellitus. Indian J Endocrinol Metab 2012;16:33-43.

5. Jyotsna VP. Prediabetes and type 2 diabetes mellitus: Evidence for effect of yoga. Indian J Endocr Metab 2014;18:745-9.

6. Saurabh S, Sarkar S, Selvaraj K, Kar SS, Kumar SG, Roy G. Effectiveness of foot care education among people with type 2 diabetes in rural Puducherry, India. Indian J Endocrinol Metab 2014;18:106-10.

7. Kalra S, Bajaj S, Gupta Y, Agarwal P, Singh SK, Julka S, et al. Fasts, feasts and festivals in diabetes-1: Glycemic management during Hindu fasts. Indian J Endocrinol Metab 2015;19:198-203. 